\title{
Influence of Heat Treatment on the Properties of Wear Resistant Tungsten Carbide Embedded Nickel Base Coating Produced by Gas Thermal Spray Process
}

\author{
P. K. GHOSH, O. P. KAUSHAL ${ }^{1)}$ and S. K. SHARMA ${ }^{1)}$
}

Welding Research Laboratory, Department of Mechanical and Industrial Engineering, University of Roorkee, Roorkee-247 667, India. 1) Mechanical Engineering Department, College of Technology, G. B. Pant University of Agriculture and Technology, Pantnagar (Nainital), U. P., India.

(Received on September 2, 1991; accepted in final form on October 25, 1991)

\begin{abstract}
The hard surfacing of mild steel substrate was carried out by thermal spraying of commercially available nickel base tungsten carbide powder under oxy-acetylene flame. The influence of pre and post spray heating on the morphology, hardness and wear characteristics of the coating were studied. The increase in preheating upto $400^{\circ} \mathrm{C}$ and post spray heating upto $900^{\circ} \mathrm{C}$ was found to enhance the hardness and wear resistance of the coating. However, the properties of the coating were found to vary across the coating showing a maximum hardness and wear resistance in the region somewhere in between its surface and the interface with the mild steel. The possibilities of occurring of various kinds of transformation during spraying as well as during post spray heat treatment have been analysed as a cause of variation in distribution of property across the coating.
\end{abstract}

KEY WORDS: thermal spray; hard surfacing; nickel base tungsten carbide powder; post spray heating; microstructure; hardness wear

\section{Introduction}

The world wide attention on reclaimation of worn out metal parts and enhancement of wear life has been provoked the technologists to think for various type of hard surfacing of conventional material to a great extent. Depending upon service requirements various types of hard surfacing material has been used so far, where the process of hard surfacing such as the weld metal deposition, plasma spraying, thermal spraying etc. has been primarily decided on process economy and suitability of application to the components. Out of various hard surfacing processes the thermal powder spray technique has been found as a comparatively cheeper and versatile process. The hard surfacing materials are generally eutectic alloys based on cobalt, nickel, tungsten, chromium etc. having dispersion of various types of carbides. Thus, during deposition of powder at high temperature the occurrence of various types of transformation in it is inevitable which, governs significantly the properties of the coating. Moreover, during deposition some kind of powders may form some metastable phases in the coating which may become stable by further transformation through a diffusion process under a post spray heat treatment and may provide a positive influence towards the wear resistance property of the coating. The utility of post spray heat treatment in improvement of the hardness of thermal spray coating has already been marked in an earlier work. ${ }^{1)}$ However, sufficient work has not been reported so far to form a clear cut understanding in this direction, so that an effective post spray heat treatment can be designed for the coatings of various systems.

To develop a further understanding in this area an investigation has been carried out to study the influence of post spray heat treatment on the properties of a nickel base tungsten carbide dispersed coating produced on mild steel substrate by thermal spray of powder technique. In this work an effort has also been made to analyse the possibilities of occurring various kinds of transformations during the entire process affecting the characteristics of the coating.

\section{Experimental}

\subsection{Hard Surfacing}

The hard surfacing of plain carbon (mild) steel was carried out by thermal spraying of nickel base tungsten carbide powder of type EWAC (1002 ET). The carbon content of mild steel and the nickel base tungsten carbide powder, as shown in Table 1, was determined by infrared analyser. The thermal spraying was performed under practically neutral flame of oxy-acetylene gas, where the pressure of oxygen and acetylene was maintained at 3 and $1.2 \mathrm{~kg} / \mathrm{cm}^{2}$ respectively. Spraying was always carried out at a torch speed of $10 \mathrm{~cm} / \mathrm{min}$. 
Prior to thermal spraying the surface of mild steel substrate was cleaned mechanically by using emery paper of Grade 400 followed by scrubbing with acetone. The spraying was carried out on the substrate preheated at 300 and $400^{\circ} \mathrm{C}$. Preheating of the substrate was carried out inside an electric muffle furnace. The coated samples were given a post spray heat treatment inside the electric muffle furnace for one hour at temperature of 600,800 and $900^{\circ} \mathrm{C}$.

\subsection{Metallography and Microhardness Study}

The transverse section of coated samples, obtained by sectioning the same, was prepared by standard metallographic procedure. The polished specimens were etched in $5 \%$ alcoholic nitric acid solution and studied under optical microscope. The area fraction of carbide particles in the coating was estimated under optical microscope by following the standard point counting method. ${ }^{2)}$ The matrix microhardness across the substrate to coating, with reference to its interface, was studied by using a load of $50 \mathrm{~g}$. The microhardness of carbide particles embedded in the coating was also studied by using a load of $100 \mathrm{~g}$.

Table 1. Carbon analysis of mild steel and nickel base tungsten carbide powder.

\begin{tabular}{ccc}
\hline $\begin{array}{l}\text { Carbon } \\
\text { content }\end{array}$ & Mild steel & $\begin{array}{c}\text { Nickel base tungsten } \\
\text { carbide powder }\end{array}$ \\
\hline$w 1 \%$ & 0.205 & 2.449 \\
\hline
\end{tabular}

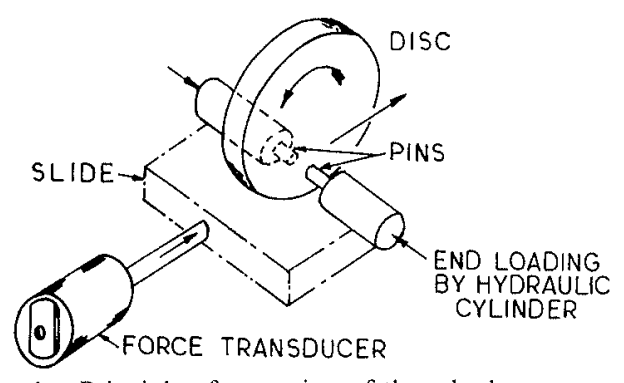

Fig. 1. Principle of operation of three body wear test.

\subsection{Wear Test}

The wear characteristics of the coating was studied by pin on disc method as shown schematically in Fig. 1. The pins as schematically shown in Fig. 2, were fabricated from the coated samples treated under different conditions. An universal carburendum green grinding wheel of specification GC $60 \mathrm{~K} 5-\mathrm{VG}$ was used as the moving disc for wear test. During the wear test, the rotation of disc and the pressure on each pins were maintained at $240 \mathrm{rpm}$ and 1 bar respectively. The wear characteristics of the coating, prepared by using various pre and post heating, were evaluated by their co-efficient of friction $(\mu)$, rate of volume of wear and rate of average depth of wear, when they are estimated as

$$
\mu=F / 2 L
$$

Rate of volume of wear

$$
=43.53\left(d_{1}-d_{2}\right)-0.2267\left(d_{1}^{3}-d_{2}^{3}\right) / t
$$

Rate of average depth of wear $=0.866\left(d_{1}-d_{2}\right) / t$

where, $\quad F$ : tangential force $(\mathrm{g})$

$$
\begin{aligned}
L=k p: & \text { end load on hydraulic cylinder }(\mathrm{g}) \\
P: & \text { pressure on pin (bar) } \\
k: & \text { constant } \\
d_{1}: & \text { diameter of pin at conical side before } \\
& \text { each machine run }(\mathrm{mm}) \\
d_{2}: & \text { diameter of pin at conical side after each } \\
& \text { machine run }(\mathrm{mm}) \\
t: & \text { wear time }(\mathrm{sec}) .
\end{aligned}
$$

\section{Results and Discussions}

\subsection{Microstructure}

The microstructure of mild steel substrate having typical ferrite-pearlite morphology has been depicted in Fig. 3.

A typical macrograph of the coating on mild steel has been shown in Fig. 4. The thickness of coating has been found to lie in the range of 0.17 to $0.34 \mathrm{~mm}$. The micrograph shows the presence of hard carbide particles embedded in the coating. At a given preheating of

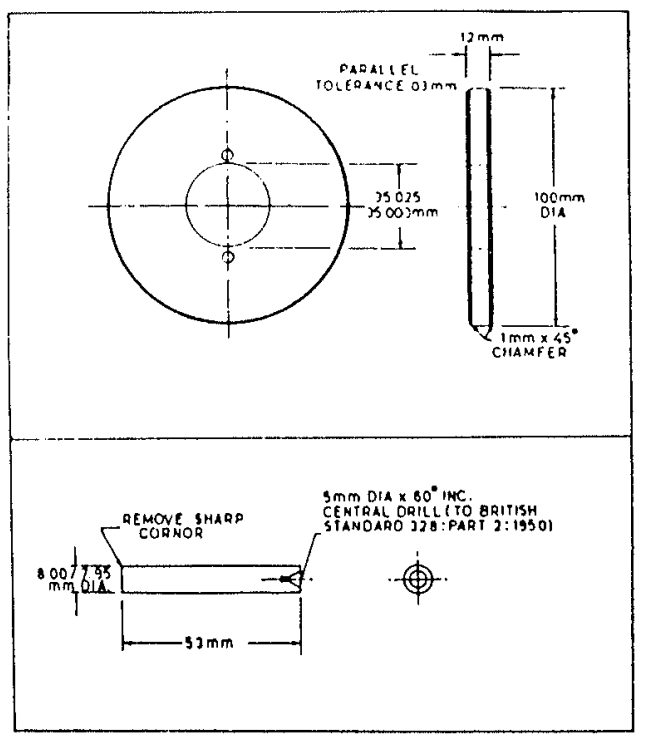

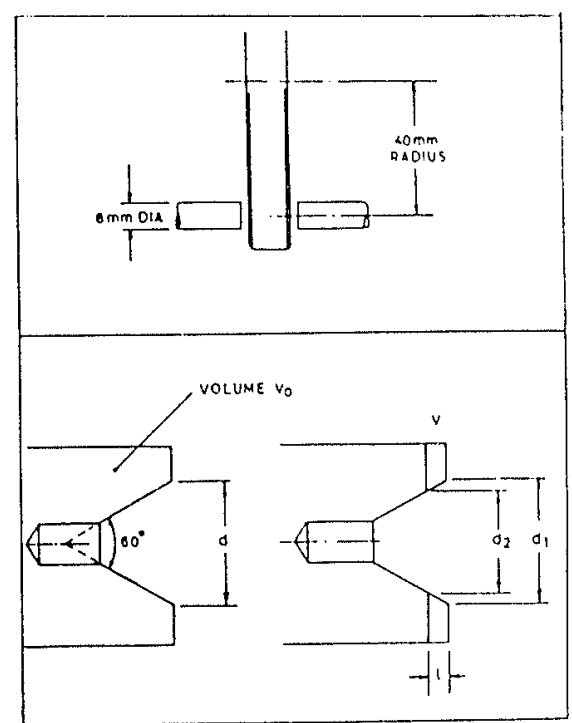

Fig. 2.

Schematic diagram of the pin. 
$300^{\circ} \mathrm{C}$ the influences of without post spray heating and the post spray heating for $15 \mathrm{~min}$ at 600 and $900^{\circ} \mathrm{C}$ on the morphology of coating have been shown in the micrographs presented in Figs. 5(a), 5(b) and 5(c) respectively. Similarly at a given preheating of $400^{\circ} \mathrm{C}$, the influences of without post spray heating and the post spray heating as mentioned above on the morphology of coating have been shown in the micrographs presented in Figs. 6(a), 6(b) and 6(c) respectively. The Figs. 5(a) to 5(c) and 6(a) to 6(c) reveal that the increase in post spray heating temperature show a tendency to reduce comparatively the amount of hard carbide particles in the matrix. The influence of enhancement in post heating temperature on the comparative reduction in area fraction of hard particles in the coating has been further depicted in Fig. 7. The reduction in amount of hard particles with the increase in post heating tem- perature, may have been primarily resulted from the solutionization of certain amount of carbide particles in the matrix.

\subsection{Microhardness}

At a given preheating temperature of 300 and $400^{\circ} \mathrm{C}$, the influences of without post spray heating and post spray heating at temperatures of 600,800 and $900^{\circ} \mathrm{C}$, on the microhardness behaviour across the coating are shown in Figs. 8 and $\mathbf{9}$ respectively. The figures show that at both the cases of preheating, the increase in post heating temperature enhances the hardness of coating significantly and the increase in hardness of coating is found to be comparatively more when a higher preheating temperature is used. The significant increase in hardness of coating prepared by using a preheating and post heating temperatures of 400 and $900^{\circ} \mathrm{C}$

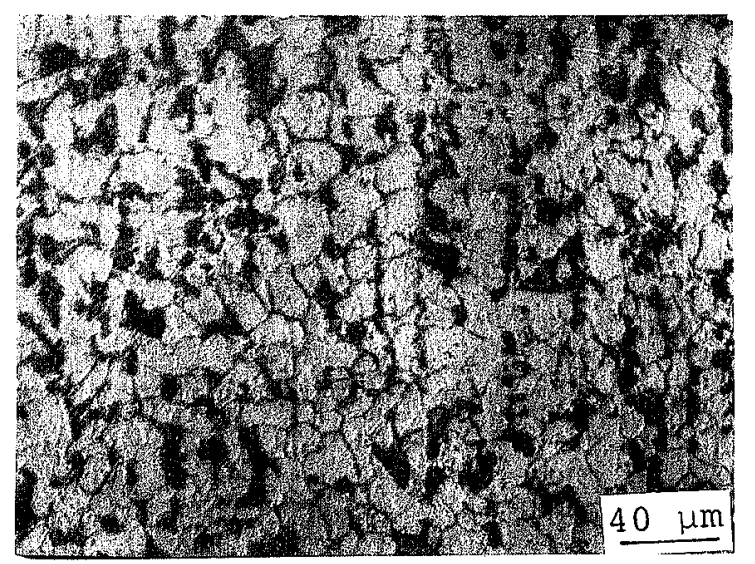

Fig. 3. Microstructure of the base metal.

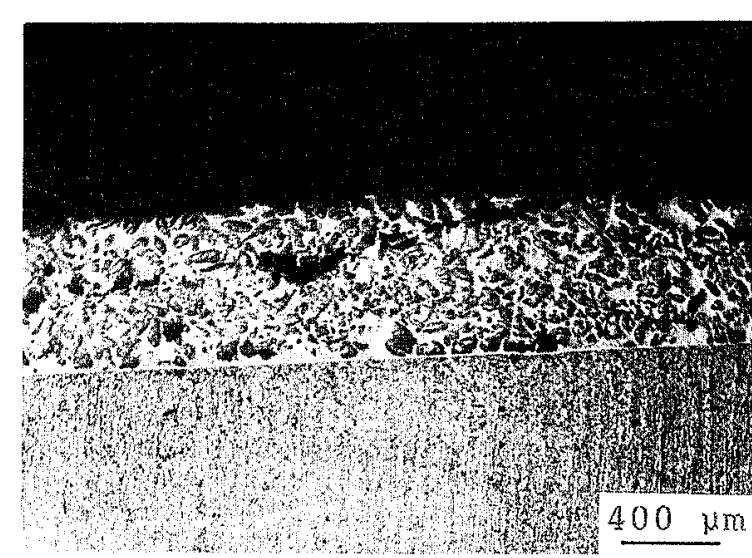

Fig. 4. Typical macrograph of the coating.

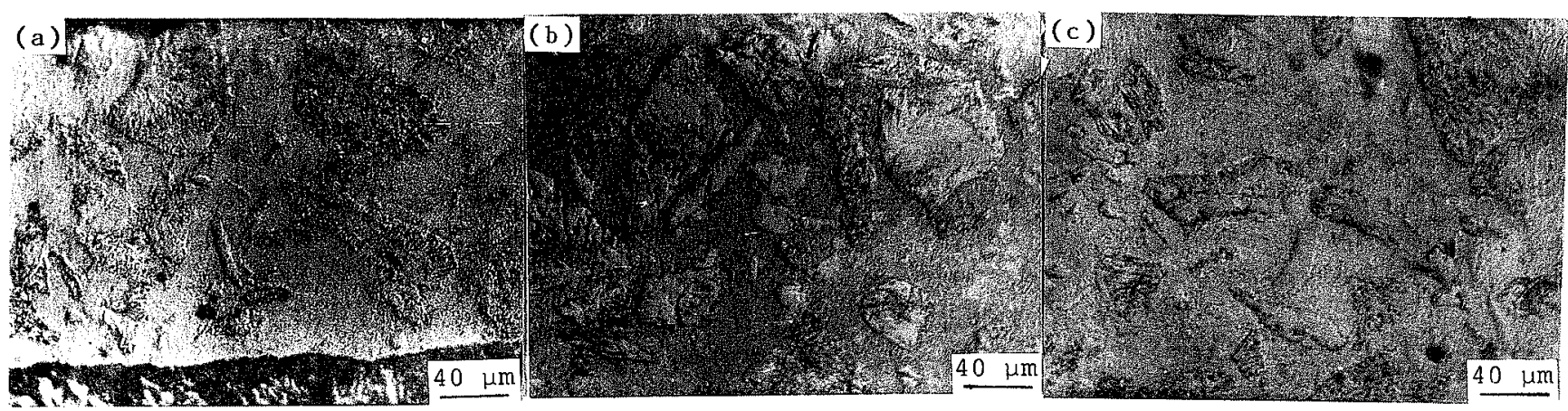

Fig. 5. At a given preheating of $300^{\circ} \mathrm{C}$ the effect of post spray heating on the morphology of the coating; (a) nil, (b) $600^{\circ} \mathrm{C}$ and (c) $900^{\circ} \mathrm{C}$.

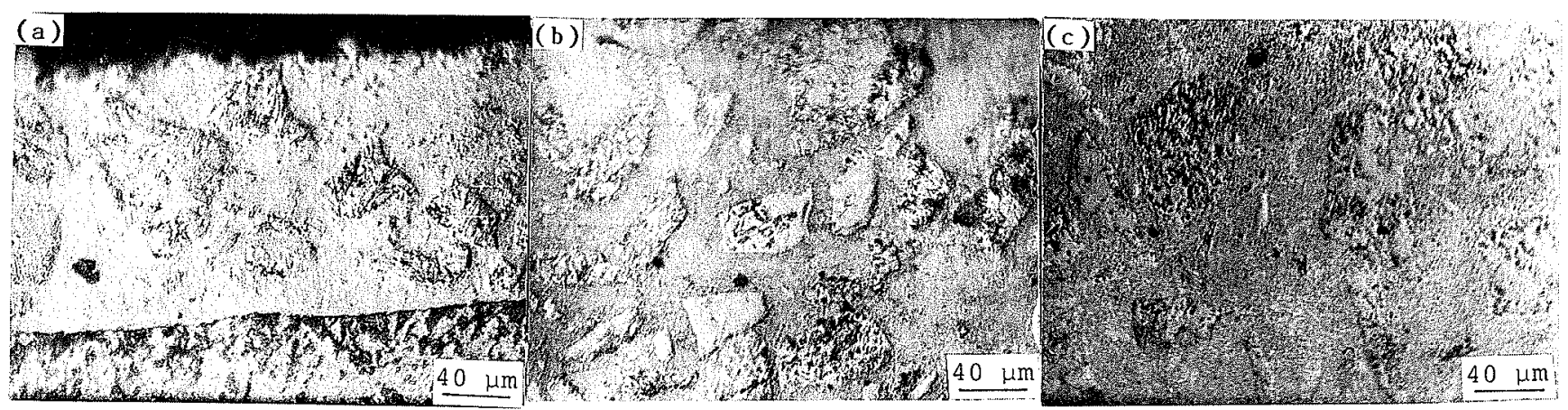

Fig. 6. At a given preheating of $400^{\circ} \mathrm{C}$ the effect of post spray heating on the morphology of the coating; (a) nil, (b) $600^{\circ} \mathrm{C}$ and (c) $900^{\circ} \mathrm{C}$. 


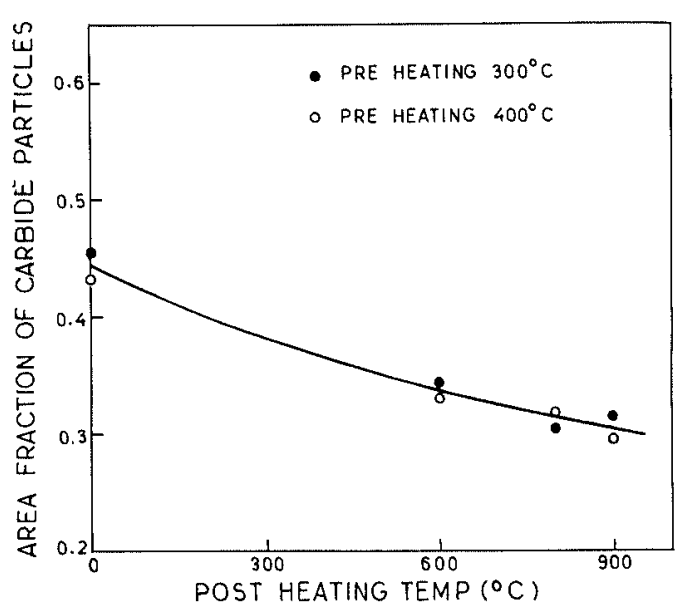

Fig. 7. The influence of post heating temperature on the hard particle content of the coating. respectively in comparison to that observed in case of coating prepared by using the pre and post heating temperatures of 300 and $600^{\circ} \mathrm{C}$ respectively has been typically evident by the size of indentation revealed in the micrographs presented in Figs. 10(a) and 10(b) respectively. At the given preheating temperatures of 300 and $400^{\circ} \mathrm{C}$, the nature of increase in peak hardness of the coating with the increase in post heating temperature has been shown in Fig. 11. In both the Figs. 8 and 9 it is also interesting to note that the peak hardness of coating lies somewhere in between the surface of the coating and its interface with the mild steel. It is further marked that the distance of peak hardness region of coating from the interface moderately enhances with the increase in post heating temperature as well as with the decrease in preheating temperature as revealed in Fig. 12.
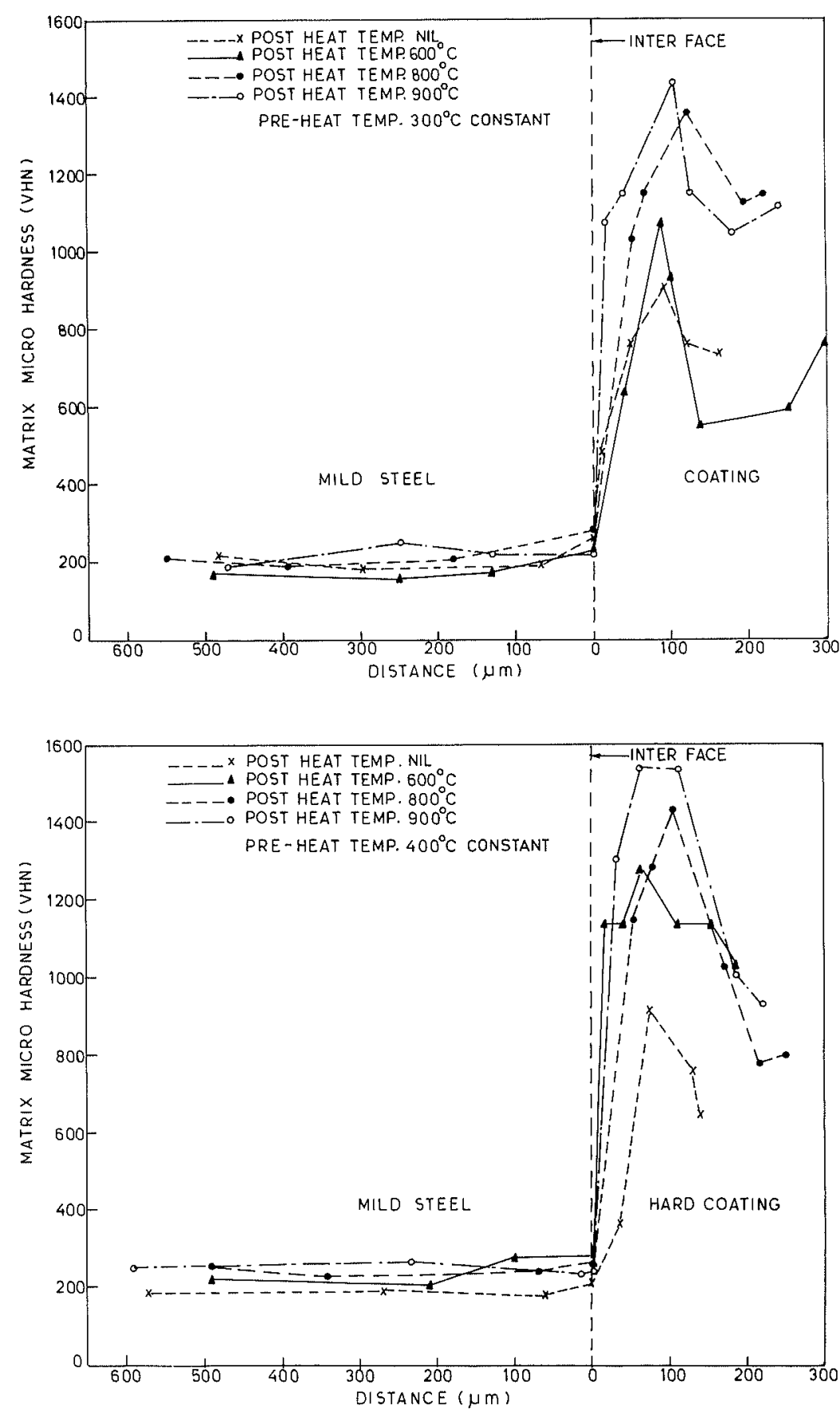

Fig. 8.

At a given preheating of $300^{\circ} \mathrm{C}$ the effect of post spray heating on the microhardness across the coating.
Fig. 9.

At a given preheating of $400^{\circ} \mathrm{C}$ the effect of post spray heating on the microhardness across the coating. 


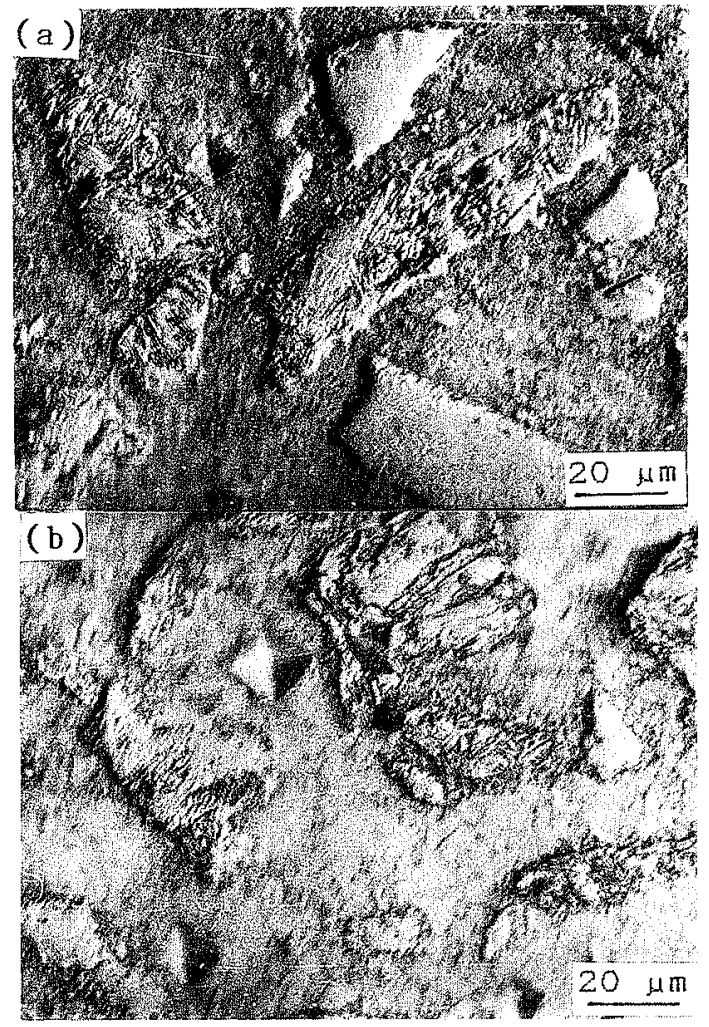

Fig. 10. The variation in coating hardness under different combinations of pre and post spray heating evident by microhardness indentation; (a) preheating $=400^{\circ} \mathrm{C}$ and postheating $=900^{\circ} \mathrm{C}$ and (b) preheating $=300^{\circ} \mathrm{C}$ and postheating $=600^{\circ} \mathrm{C}$.

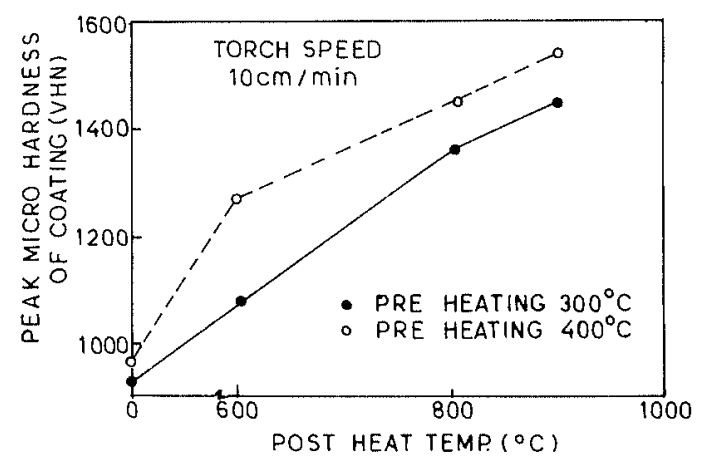

Fig. 11. Al a given preheating the influence of postheating on the peak hardness of the coating.

In the coated layer the hardness of embedded carbide particles has been found to show a tendency to be comparatively lowered with the increase in their distance from the interface as shown in Fig. 13. This behaviour has been found to be comparatively more pronounced in case of higher preheating temperature of $400^{\circ} \mathrm{C}$. However, at a given preheating the average hardness of embedded carbide particles in the coating as well as its standard deviation has to some extent been found to be enhanced with the increase in post heating temperature as shown in Fig. 14.

During hard surfacing under oxy-acetylene flame the temperature may become high enough to transform certain amount of tungsten carbide to $\mathrm{W}$ and $\mathrm{W}_{2} \mathrm{C}$. The transformation may be further enhanced with the increases in preheating temperature. During subsequent

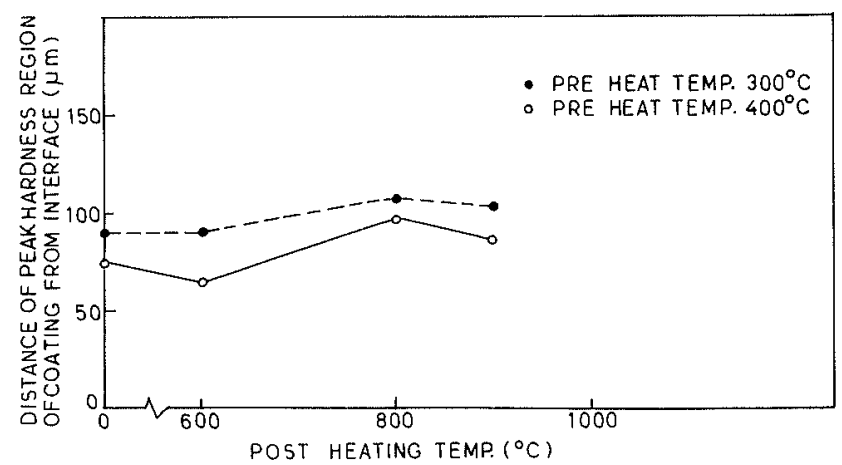

Fig. 12. The effect of pre and post heating on the position of peak hardness region of the coating with reference to its interface.

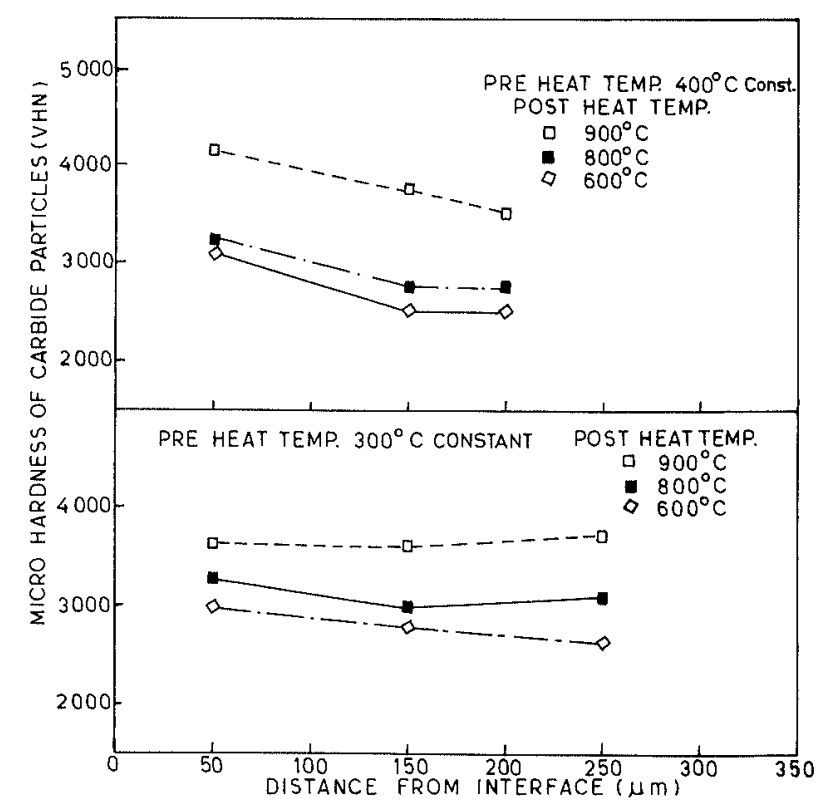

Fig. 13. At different pre and post heating temperatures the hardness of carbide particles observed at different distances from the interface.

cooling the $\mathrm{W}$ may form a fine dispersion of $\mathrm{WC}$ in the matrix and enhance its hardness. However, the formation of WC is primarily dependent on the availability of carbon in the nickel base matrix, the amount of which may be reduced as one approaches the interface of the coating with the mild steel. This may happen due to diffusion of carbon from the coating to the mild steel. The diffusion of carbon in the region of mild steel close to the interface is clearly marked by the formation of a significant amount of carbon rich dark second phase in this region as shown in Figs. 5(a) and 6(a). This behaviour may have reduced the matrix hardness of the coating in its region close to the interface as shown in Figs. 8 and 9. However, the reduction in matrix hardness of the coating in the region close to its surface (Figs. 8 and 9) may have happened due to oxidation of carbon and a certain amount of $\mathrm{W}$ and $\mathrm{WC}$ to $\mathrm{WO}_{3}$ at temperature beyond $565^{\circ} \mathrm{C}^{3)}$ The increase in matrix hardness of the coating with the increase in post heating temperature (Figs. 8 and 9) may have been caused by the further enhancement in formation of fine carbides in the matrix and it 


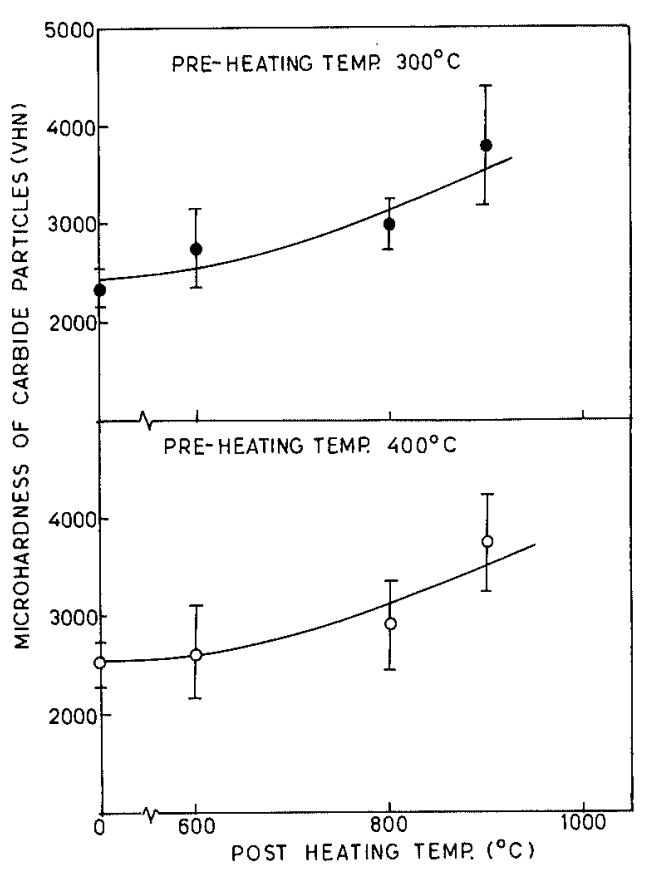

Fig. 14. At a given pre heating the influence of post heating on the average hardness of the carbide particles.

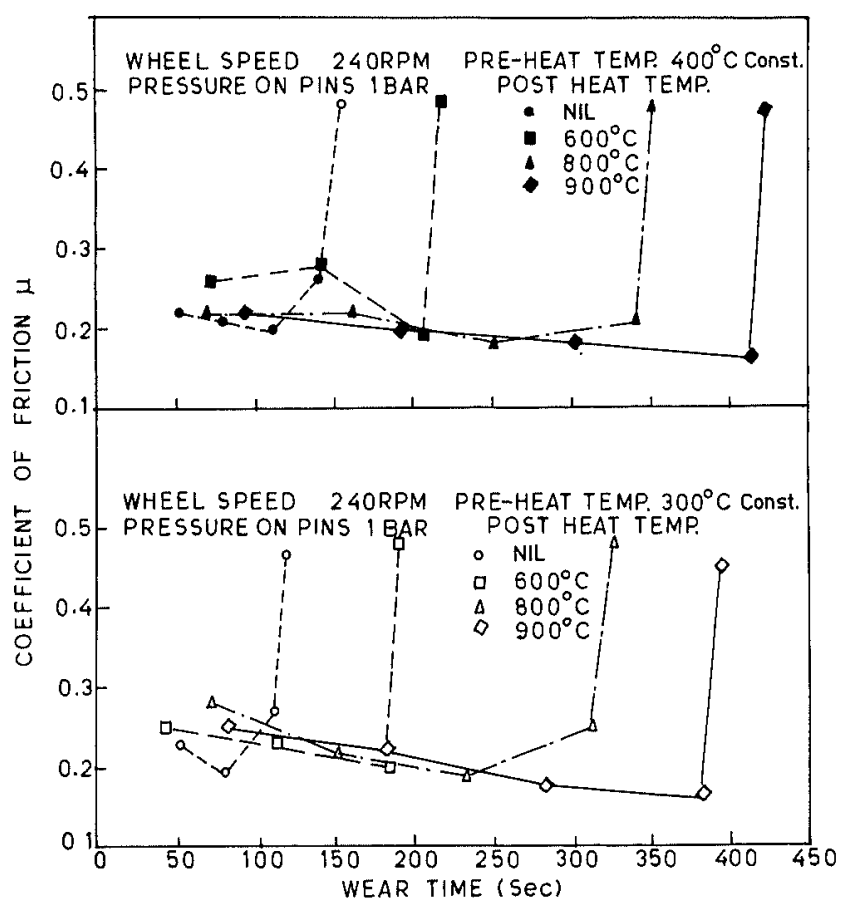

Fig. 15. At a given pre heating the influence of post heating on the co-efficient of friction of the coating observed at different wear time.

is further favoured by higher preheating temperature (Fig. 11).

During post spray heating the increase in average hardness of tungsten carbide particle with the enhancement of post heating temperature (Fig. 14) may have been caused by the transformation of $\mathrm{W}_{2} \mathrm{C}$ to $\mathrm{WC}$ by consumption of free carbon available in the carbide particles as well as in the matrix. ${ }^{4)}$ In case of post spray heating the comparative increase in hardness of embedded carbide particles with the decrease in distance from the interface (Fig. 13) posssibly caused by the

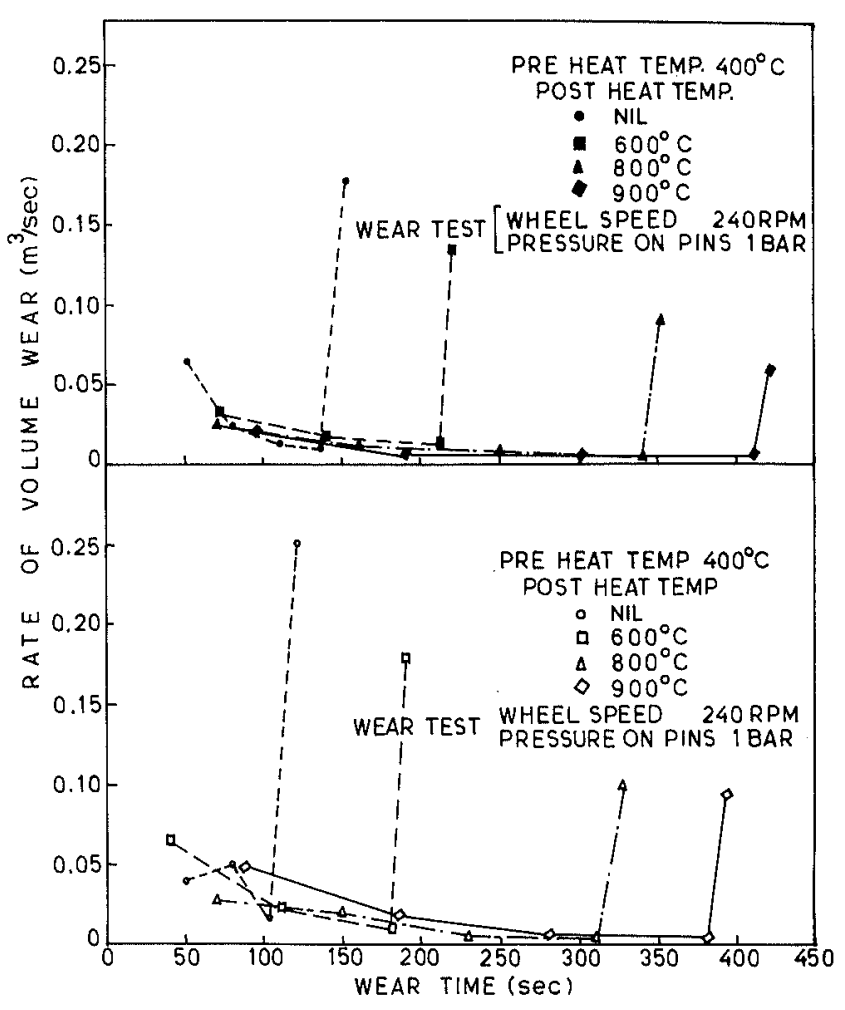

Fig. 16. At a given pre heating the influence of post heating on the rate of volume of wear of the coating observed at different wear time.

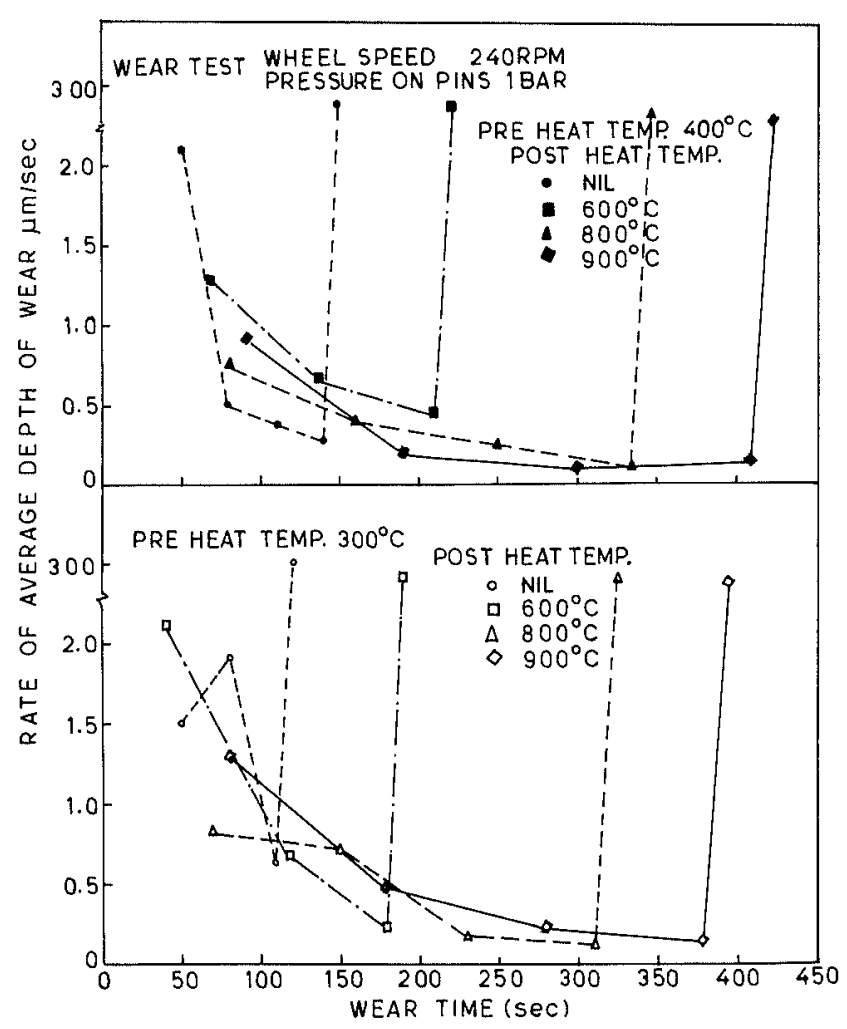

Fig. 17. At a given pre heating the influence of post heating on the rate of average depth of wear of the coating observed at different wear time.

more availability of carbon than that available in the region close to coating surface as discussed above. However, the detail verification of the basic phenomena discussed above could not be made in this work as they 
were beyond the scope of this investigation. A further work in this direction may be carried out in detail, which may be beneficial to improve the quality of this type of wear resistant coating obtained by thermal spray of powder technique.

\subsection{Wear Properties}

In both the cases of preheating at 300 and $400^{\circ} \mathrm{C}$, the observed behaviour of change in co-efficient of friction at different duration of wear of the coating, having no post spray heating and post spray heating at 600,800 and $900^{\circ} \mathrm{C}$, has been shown in Fig. 15. Similarily the change in rate of volume of wear and the change in average depth of wear at different duration of wear observed in case of coatings prepared under various conditions of preheating and post spray heating as said above, are shown in Figs. 16 and $\mathbf{1 7}$ respectively. The Figs. 15, 16 and 17 show that as the wear proceeds from the coating surface towards its interface, the co-efficient of friction, rate of volume of wear and the rate of average depth of wear respectively decreases significantly upto a certain wear time followed by a sudden considerable enhancement in them, indicating the characteristics of the presence of comparatively soft base metal. In all the Figs. 15, 16 and 17 it is also marked that the time required for complete wear out of the coated layer having thickness of the order of 0.17 to $0.34 \mathrm{~mm}$, enhances considerably, with the increase in post heating temperature as well as, to some extent, with the increase in preheating temperature. These behaviours are in agreement to the microhardness characteristics of the coating presented in Figs. 8, 9, 11 and 12. The improvement in wear resistance of the coating with the increase in post heating temperature may have also predominantly caused by the enhancement of the hardness of carbide particles as shown in Fig. 14. Thus, it can be inferred that the use of post spray heating improves the wear resistance of the coating significantly, which may provide a better life to this type of coating under any service condition concerning dry wear.

\section{Conclusions}

The post spray heating influences the hardness of the matrix and the embedded tungsten carbide particles by enhancing the same significantly. This improves the wear resistance of the coating to a great extent and provides a better life to the hard surface generated on the structural steel. However, a detail work should be carried out further to establish the phenomena playing a significant role in transformation of various components of the coating under post spray heating.

\section{REFERENCES}

1) H. T. Steine, P. Ackermann and W. Sim: Metal powder developments for thermal sprayed wear resistant protective coatings, Proc. Conf. Advances in Thermal Spraying, Welding Inst. Canada, Montreal, (1986), 333.

2) R. T. Dehoff and F. N. Rhines: Quantitative Microscopy, McGraw-Hill, New York, (1968), 77.

3) T. Ya. Kosolapora: Carbides Properties, Production and Applications, Plenum Press, New York, (1971), 243.

4) T. Ya. Kosolapora: Carbides Properties, Production and Applications, Plenum Press, New York, (1971), 160. 